\section{Hahn's Nobel was well deserved}

SIR - I read with interest the report ${ }^{1}$ on the internal debates in the Nobel committee that preceded the award of the Nobel prize to Otto Hahn in 1945. I am one of the few surviving witnesses of Hahn's studies leading to the discovery of uranium fission, although I knew nothing at the time about the details.

As a young theoretical physicist, I worked for six months in 1936 with Lise Meitner in her section of the Kaiser-Wilhelm-Institut für Chemie in Berlin-Dahlem, of which Hahn was the director. I then went to the Kaiser-Wilhelm-Institut für Physik, also in Berlin-Dahlem, five minutes' walk away. In the last week of 1938, Hahn telephoned and asked me: "Can you imagine a radium which in every chemical separation does not go with radium but with barium?" I asked: "Do you have such a substance?" $\mathrm{He}$ answered "Yes". I said: "Perhaps it is really barium." He said: "Yes, but then the uranium nucleus must have been split." This shows that he really had discovered and identified the splitting of uranium. But, as an empirically working chemist, he felt somewhat uncertain about it and so he asked me, as a theoretical physicist, whether I believed it.

When he wrote to Meitner, who was then in Sweden, he was similarly cautious. From members of his institute, I soon learned that Hahn and Meitner had discussed the problem before she left his institute in the late summer of 1938. Several years previously, Frédéric Joliot in Paris had bombarded uranium with neutrons and produced a substance that he interpreted as a radium isotope. This was very difficult for a physicist such as Meitner to believe. Hahn said: "I must study those 'radium isotopes' of Joliot's." Meitner said: "It isn't worth the effort. It must be an error. It's nonsense." But as soon as she had left the institute, Hahn, with Strassmann, started to repeat Joliot's experiment, and he found the chemical behaviour of barium. Some members of Hahn's institute later told me: "If Lise Meitner had stayed in Berlin, it is quite possible that Hahn would not have started this experiment and so would not have been the one who discovered uranium fission."

When Meitner learned from Hahn's letter what he had found, she, with Otto Frisch, invented a correct model of the process, that is, she confirmed his empirical result by finding a theoretical description of its possibility. It is true that she used a theoretical model of the nucleus invented by Niels Bohr, but it was she and Frisch who first applied it to Hahn's discovery, which they knew about from Hahn's letter before it was published. But she had private contact with Bohr, who confirmed her conclusion.

Thus it was right to give the Nobel prize for chemistry to Hahn (or perhaps to Hahn and his collaborator Strassmann). Whether Meitner (perhaps with Frisch, that excellent theoretician) should have been given the prize for physics for first confirming the theoretical correctness of Hahn's interpretation of his result is an open question. I think Hahn himself would gladly have accepted that. But the discovery itself was clearly Hahn's.

\section{Carl Friedrich v. Weizsäcker}

Maximilianstrasse $14 \mathrm{c}$

D-82319 Starnberg,

Germany

SIR - Crawford et al. ${ }^{1}$ deserve credit for their Commentary article in which they shed more light on the circumstances leading to the award in 1945 of the 1944 Nobel prize to Otto Hahn.

However, their statement that "Hahn and his colleagues immediately began writing Meitner out of the discovery of nuclear fission" when, on 6 August 1945, during their detention at Farm Hall, they heard about the atomic bomb on Hiroshima, is a rather one-sided portrayal.

As can be seen from reports by Major T. H. Rittner, their British 'host' at Farm Hall, the detainees became very worried about reports in the next day's newspapers of their alleged work on the atomic bomb in Germany. At Rittner's suggestion, therefore, on 8 August 1945 the Germans drew up a memorandum setting out their side of the story ${ }^{2}$. One of the issues dealt with in the memorandum was the discovery of nuclear fission, which in the newspapers was attributed only to Meitner ${ }^{3}$.

The authors are right to consider the memorandum as showing the Farm Hall detainees "writing Meitner out of the discovery of nuclear fission". But it would have been fair to have stated that the detainees were reacting to newspaper reports that mentioned only Meitner as the discoverer.

\section{Jan H. J. Oelering}

Hofwijkstraat 4,

6825 Al Arnhem,

The Netherlands

1. Crawford, E., Sime, R. L. \& Walker, M. Nature 382. 393-395 (1996).

2. Operation Epsilon: The Farm Hall Transcripts, 93 (Institute of Physics, Bristol, 1993)

3. Sime, R. L. Lise Meitner: A Life in Physics, 323 (University of California Press, 1996)

\section{No funeral in Berlin}

SIR - Alison Abbott recently reported on the poor financial health of the Berlin universities, particularly the "nearly bankrupt Free University" (Nature 382, 486; 1996). The impression was conveyed that demise is imminent and condolences are in order.
It is true that we are suffering from budget cuts more than non-university research institutions. The well-being of the universities is evidently not high on our politicians' priority list. For example, the decision not to house the Institute for Molecular Pharmacology in existing buildings close to the medical school of the Free University but, instead, to erect a new building on the site of a non-university institution, is just another instance of the political myopia that fails to see how the quality of university research will be reflected in the qualifications of the next generation of researchers. Nevertheless, I am happy to report that more than 700 full professors, about 3,000 scientists, and 49,000 students are still working hard and successfully at the Free University of Berlin. So we are suffering because of shortsighted politics but wreaths are premature.

\section{Klaus Roth}

Free University of Berlin,

Thielallee 66,

D-14195 Berlin,

Germany

\section{Plants and AIDS}

SIR - The News story "Chemistry professor takes over Islamic science organization" (Nature 382, 487; 1996) incorrectly states that a claim has been made that our institute is close to finding a therapy for AIDS. The article was apparently based on a distorted press version of our interesting discovery of four plants that are active against HIV-I. A clarification by us was subsequently published in the national Urdu newspaper Jang.

We initiated a collaborative programme with the US National Institutes of Health (NIH) in Bethesda, Maryland, about four years ago to search for plants with anticancer and anti-AIDS activities. Plants are collected from remote areas of Pakistan, extracted and the extracts subjected to screening at NIH. As result of this programme, we have discovered four plants with varying degrees of activity against the HIV-I virus.

The active plants are subjected to bioassay-directed fractionation in order to isolate the bioactive constituents. Although we consider the discovery of plants with anti-AIDS activity exciting, we do not claim to be close to finding a "therapy for AIDS". We are at present actively seeking collaboration with hospitals specializing in the treatment of AIDS patients in order to carry out double-blind clinical trials on the phytochemical preparations.

\section{Atta-ur-Rahman}

(Director)

H.E.J. Research Institute

of Chemistry,

University of Karachi,

Karachi, Pakistan

e-mail: hejric@biruni.erum.com.pk 